Deep Sclerectomy with supraciliary hema implant (Esnoper ${ }^{\circledR}$ V-2000):

\title{
Results and complications
}

\section{Authors:}

Jordi Loscos Arenas*, MD PhD; Xavier Valldeperas*,MD, PhD, FEBO; Klaus Langohr** PhD ; Àngels Parera* MD, Miquel Domingo* MD, Antoni Sabala* MD, Julio de la Cámara* MD PhD.

* Department of Ophthalmology, Hospital Universitari Germans Trias i Pujol, Barcelona, Spain.

**Departament d'Estadística I Investigació Operativa, Universitat Politècnica de Catalunya, Spain

\section{Correspondence and reprints:}

Jordi Loscos Arenas

Hospital Universitari Germans Trias i Pujol

Servei d'Oftalmologia

Carretera de Canyet s/n

08916 Badalona

Fax number: 934978843.

Telephone number: +34932120445

jordiloscos4@hotmail.com 


\section{Introduction}

Deep sclerectomy (DS) is a non-penetrating procedure for the treatment of open angle glaucoma (OAG) that can be enhanced with the use of antimetabolites, such as mitomycin C (MMC) or 5-fluorouracil, as well as implants. These devices are placed to facilitate the aqueous outflow by maintaining the virtual space created after removing the deep scleral flap. There is proof of the good long-term outcomes of its implantation in the scleral bed but there are few reports of the placement of the implant in the supraciliary space and, until now, it is not known if this produces a higher reduction in IOP than in the scleral space $(1,2)$. Hyphema, bleb leakage (seidel) and goniopuncture for insufficient filtration through the trabeculodescemetic membrane (TDM) are the most common complications after supraciliary and intrascleral fixation. The incidence of hyphema after classic glaucoma surgery has been widely described, but no correlation with intraocular pressure (IOP) has been found. New glaucoma surgical procedures and new devices have different type and rate of complications, with implications that have been scarcely reported in the literature.

\section{Material and Methods}

Forty-eight eyes of 41 patients with OAG, who underwent DS with supraciliary hema implant between October 2008 and July 2010, were included in this study. All surgeries were performed by the same surgeon (JLA). Table 1 shows clinical and demographic characteristics of the patients in the study. Uneventful phacoemulsification was performed in 14 eyes 6 months before the DS. All patients were over 18 years old and suffered from uncontrollable OAG, primary or secondary, under maximal tolerable medical treatment or unable to fulfill the treatment. All the patients signed the consent form approved by the Department of Ophthalmology of the Hospital Germans Trias i Pujol, Barcelona, Spain.

All surgeries were performed under peribulbar anesthesia. The surgical procedure was performed following the technique first described by Mermoud (3) with the modifications suggested by Muñoz (1) for the insertion of the implant 
in the supraciliary space. MMC $(0.02 \%)$ was used on all patients for 3 minutes and washed thoroughly with balanced salt solution (20-30 mL). The hema implant (Esnoper ${ }^{\circledR}$ V-2000, AJL Ophthalmics, Álava, Spain) was placed in a full thickness scleral pocket, made with a $45^{\circ}$ blade for the incision and a blunt spatula, $2 \mathrm{~mm}$ behind the scleral spur, fixed without suturing. The superficial scleral flap was reflected back and sutured with a 10/0 nylon. Postoperative treatment consisted of topical ofloxacine $0.3 \%$ three times daily for one week and prednisolone acetate $10 \mathrm{mg} / \mathrm{ml}$ six times a day that tapers over six weeks. Goniopuncture with Nd-Yag laser (Visulas ${ }^{\circledR}$ Ophthalmic Zeiss Instruments) was performed when insufficient filtration was observed through the TDM. At the time of the goniopuncture, an argon iridoplasty was performed on phakic eyes and eyes with convex peripheral iris or not very open angle.

A complete preoperative ophthalmologic examination was done in all patients, including best-corrected visual acuity (BCVA) using Snellen decimal scale, IOP measurement with Goldman tonometer, visual field analysis (Humphrey ${ }^{\circledR}$-Ophthalmic Zeiss Instruments. Jena, Germany), corneal pachymetry (UP-1000 ${ }^{\circledR}$, Nidek, Japan) and gonioscopy. Follow-up visits were scheduled at 24 hours, 1, 3, 6, 12 and 24 months after the surgery and all visits included BCVA, anterior and posterior segment examination, tonometry and gonioscopy. Ultrasound biomicroscopy (UBM) (VuMax ${ }^{\circledR} 35 / 50$ Sonomed $^{\circledR}$ Lake Success - NY, USA), visual field analysis, optic nerve photography or optical coherence tomography (OCT) (Stratus $3000^{\circledR}$, Ophthalmic Zeiss Instruments. Jena, Germany) were performed at the discretion of the investigator when glaucoma progression or complications were suspected. The use of topical antihypertensive drops and goniopuncture was also recorded.

The implant used in all the surgeries was the Esnoper ${ }^{\circledR}$ V-2000 (AJL Ophthalmics - Álava, Spain). It is a non-absorbable hema (2-hydroxyethyl methacrylate) implant designed to prevent the collapse of the intrascleral lake. It can be placed in the intrascleral or in the supraciliary space during DS procedure (2).

Complications of the procedure are detailed in Table 2. Postoperative complications were classified in early or late complications, if they took place 
before or after one month. Intraoperative complications are those occurred during the surgical procedure. Eyes that needed trabeculectomy conversion during DS surgery were excluded and were not considered for analysis purposes. Goniopuncture was not considered as a complication, except if it was performed before one month after the surgery, meaning an insufficient TDM dissection during surgery. Complications attributable to the goniopuncture were hypotony longer than 2 weeks, iris incarceration, and bleeding, with or without hyphema formation. Complications related to the bleb were the need for additional MMC injections.

Statistical analysis

For the descriptive analysis of the data, numerical indicators were calculated in case of quantitative variables -mean, median, standard deviation, and range-, and categorical variables were presented in absolute and relative frequencies (\%). To analyze the efficacy of the treatment, in terms of IOP reduction a linear mixed model was used relating the IOP separately with each of the variables of interests, and including the variable 'Patient' as a random effect. Contrary to standard statistical test these models account for the correlation of the data from the same patient. Standard tests as the t-test or the Wilcoxon test could not be used, because they assume data are independent, which is not the case with our data. All the statistical analyses have been carried out with the statistical package $\mathrm{R}$, version 2.13.1. Results of statistical tests were considered statistically significant when $p<0.05$ (4).

\section{$\underline{\text { Results }}$}

Table 3 shows the mean IOP and number of hypotensive drugs change. Postoperative mean IOP at 12 months was $16.5 \pm 4.4 \mathrm{mmHg}$ with a reduction from preoperative value of $7.9 \mathrm{mmHg}(32.1 \%)$, showing statistical significance $(p<0.001)$. Postoperative IOP at 24 months was $16.1 \pm 3.4 \mathrm{mmHg}$ with a reduction from a preoperative value of $8.2 \mathrm{mmHg}(33.7 \%)$, showing statistical significance $(p<0.001)$. The number of glaucoma medications also decreased from $2.71 \pm 0.7$ drugs per patient preoperatively to $0.22 \pm 0.1(p<0.001)$ at 12 month, and $0.4 \pm 0.1(p<0.001)$ at the end of study. 
Goniopuncture with the Nd:Yag laser was performed in 30 eyes (62.5\%), with a mean time between the surgery and the procedure of 150 days, producing a mean IOP reduction of $4.0 \mathrm{mmHg}(\mathrm{p}<0.001)$. Argon iridoplasty was performed in 7 eyes (23.3\%). Four eyes (13.3\%) had a small bleeding after goniopuncture without hyphema formation, 1 hypotony (3.3\%) and 1 partial iris incarceration (3.3\%) in the TDM. Preoperative BCVA in Snellen decimal chart was $0.6 \pm 0.3$ and postoperative BCVA, 12 and 24 months after the surgery, were $0.6 \pm 0.2$ and $0.7 \pm 0.2$, respectively. All the complications are summarized in Table 2. The only intraoperative complication was the microperforation of the TDM in 1 eye (2.08\%). The main early postoperative complication was seidel at 24 hours in 11 eyes (22.91\%) without flat anterior chamber, spontaneously resolved 72 hours after surgery in all cases except in 2 cases (4.16\%) that needed resuturing four days after surgery. Hyphema was observed in 7 eyes (14.58\%), choroidal detachment in 3 eyes (6.25\%) and additional MMC injections were necessary in 2 eyes (4.16\%) (Table 4). The presence of hyphema during the postoperative period was further analyzed. Twelve months after the surgery $(n=48)$, mean IOP was $19.3 \pm 4.3 \mathrm{mmHg}$ in the 7 eyes with hyphema and $16 \pm 4.4 \mathrm{mmHg}$ in eyes without (41 eyes). Twenty-four months after the surgery mean IOP was $18 \pm 2.8 \mathrm{mmHg}$ in the hyphema group (6 eyes) and $15.6 \pm 3.5 \mathrm{mmHg}$ in eyes without hyphema (27 eyes) (Figures 1 and 2). No correlation between hyphema and final IOP were found at 12 months $(p=0.111$ ) but a significant correlation was observed 24 months postoperatively $(p=0.048)$.

\section{Discussion}

Most of the published studies about DS are using intrascleral implants or no implants. Only the study by Muñoz et al (1) reports the results with a supraciliary implant $\left(\right.$ TFlux $\left.^{\circledR}\right)$ in isolated DS, and the study by Bonilla et al (2) with the use of supraciliary Esnoper ${ }^{\circledR}$ in combined DS and phacoemulsification. Our results are comparable to the results published by Muñoz et al (1), although postoperative IOP in our patients is higher $(16.5 \pm 4.7 \mathrm{mmHg}$ compared to 14.0 $\pm 3.0 \mathrm{mmHg}$ ) and postoperative hypotensive medications per patient are lower 
(0.2 compared to 0.3 ). There are no studies published in the literature with two years follow-up and, therefore, we cannot compare our results. The rest of the existing bibliography on DS only refers to intrascleral implants or surgeries without implants. Cheng (5) compares different series with different intrascleral implants with or without MMC, confirming that the use of implants and antimetabolites are essential to improve the results of the surgery. But it is still not clear if placing an implant in the supraciliary space produces a higher reduction in IOP than in the scleral space, or a different rate of complications.

Non-penetrating surgery with supraciliary implant fixation seems to have fewer postoperative complications than intrascleral implantation. The learning curve is short for a surgeon with expertise in glaucoma surgery and it can be achieved without major complications. At the moment, though, there are no studies comparing both techniques in term of results and complications. The incidence and management of intraoperative microperforations are similar in both techniques $(1,2)$. The implantation of the Esnoper ${ }^{\circledR} \mathrm{V}-2000$ in the supraciliary space has been performed without complications in all the cases and we agree with Muñoz et al (1) that avoiding maneuvers of suture is an additional advantage to this technique. Early postoperative complications have been similar to those described in the literature with intrascleral implant. Postoperatory seidel without flat anterior chamber at 24 hours was observed in 11 cases $(22.9 \%)$. Seidel incidence according to different authors is between $7 \%$ and $14 \%$ in penetrating and non-penetrating procedures, but a completely different meaning. In non-penetrating surgery, when the anterior chamber is not shallow or flat, it can be managed with a contact lens or steroid therapy discontinuation. Although seidel is not so dangerous in non-penetrating surgeries, avoiding it undoubtedly facilitates the long-term maintenance of the subconjunctival space.

Hyphema also appears in a variable percentage in the different studies published, ranging from $0.8 \%$ (6) to $22.7 \%$ (7) when the implant is intrascleral, and in $6.6 \%$ when the implant is supraciliary (1). Hyphema is more common after trabeculectomy (8) and canaloplasty (9), where it is considered to be a positive factor. Nevertheless, the interpretation of the hyphema in nonpenetrating surgery is different. For Grieshaber (9) it is a sign of the 
reestablishment of the functionality of Schlemm's canal after canaloplasty, whereas Koch (10) holds that hyphema may appear in any surgery that produces postoperative ocular hypotension. Hamel (11) finds that the incidence of hyphema is higher in myopic eyes (19\%), but we could not find such differences. In our series it has appeared in 7 out of 48 eyes (14.58\%) and in all cases has been lower than $1.5 \mathrm{~mm}$. The origin may be an inverse reflux from the intrascleral lake to the anterior chamber through the TDM, due to the hypotension. Konstas (12) postulated that the vascular components of the sclera and ciliary body were the most likely sources of blood after trabeculectomy. When we compared the IOP, 24 hours after the surgery, in eyes with and without hyphema, there was no difference between the groups, being the mean IOP of $7.8 \mathrm{mmHg}$ in both, but at 12 and 24 months the eyes which had hyphema showed a significantly higher IOP. We found a nonsignificant correlation between the presence of hyphema and high IOP at 12 months $(p=0.111)$ that became significant at 24 months $(p=0.048)$. Our hypothesis is that the fibrotic and inflammatory stimulation caused by the blood has a negative effect on the long term IOP control. It is paradoxical that hyphema, that means postoperative ocular hypotension 24 hours after surgery, may have a poor prognostic factor in the longer term. We could not find any reference in the literature about the relationship between the presence of hyphema and bleb failure in DS. Cobb et al (13) reported a significant association between aspirin intake and a higher risk of hyphema, in trabeculectomy patients, but this did not significantly affect IOP control at 2 years. Probably, TDM in non-penetrating surgery is more vulnerable to fibrosis than trabeculectomy, even after goniopuncture.

The appearance of a choroidal detachment (CD) in DS surgery has been described between $2 \%$ and $5 \%$ of the cases, according to different series. Although the surgery with supraciliary implantation could potentially increase the incidence of this complication, neither the series of Muñoz et al (1) with TFlux ${ }^{\circledR}$ nor ours, points in this direction. In our study, CD occurred in 3 eyes (6.25\%). Two of the three cases corresponded to the same patient, a 48 yearold male with pigmentary glaucoma and high preoperative IOP $(40 \mathrm{mmHg}$ and $42 \mathrm{mmHg}$, respectively). Both eyes presented with macular folds secondary to 
hypotony that spontaneously resolved one month after the surgery. Young myopic patients are more prone to suffer from hypotony after DS with supraciliary implantation.

Uveal prolapse into the intrascleral lake is a complication scarcely described in the literature and only when intrascleral implants are used (14), probably because it is an UBM diagnosis. In our series, we have found two cases (4.16\%). The first one, a 72 year-old phakic male, was detected 5 months after the surgery. An absence of the hyporeflective suprachoroidal space and the conjunctival bleb was observed on the UBM examination (Figure 3). IOP was $14 \mathrm{mmHg}$ without topical treatment. The second case was a 60 year-old phakic patient with a complete intraoperative scleral perforation in one of the lateral incisions. Twenty-four months after the surgery, UBM exploration showed a uveal prolapse with good location of the implant and presence of the hyporeflective suprachoroidal space (Figure 4). The bleb was present and the IOP was $16 \mathrm{mmHg}$ without treatment. Uveal prolapse may not be uncommon especially with very deep procedures. Therefore, intrascleral needling should be performed very carefully.

There are no published studies comparing the complications of DS surgery placing the implant in the intrascleral or in the supraciliary space. It is not clear whether hyphema may be more frequent when the implant is placed in any of the two spaces. Blood is a widely accepted mediator of inflammation and it is also known that scarring can lead to the failure of glaucoma surgery. When hyphema occurs after DS, blood can migrate from the anterior chamber to the subconjunctival space stimulating fibrosis of the TDM and fibroblast proliferation, resulting in a late bleb failure. It is still not clear if this is more common in the supraciliary implantation, but bleeding may be favored by subtle movements of the implant when it is not completely fixed. This could induce late fibrotic phenomenon of the TDM or even forward displacement of the implant with limitation to the aqueous filtration across the TDM. Hyphema will probably be less frequent with the new implant model,that has two lateral notches specially designed for non-stitching supraciliary technique. Even that placing the implant in the supraciliary space could enhance the uveoscleral outflow it could 
be that when the implant is located into the supraciliary space the volume of the intrascleral lake could be reduced leading to less IOP reduction (1).

\section{Conclusion}

The insertion of the implant in the supraciliary space is an effective and safe surgery for patients with OAG but it is still not clear if placing an implant in the supraciliary space produces a higher reduction in IOP than in the scleral space. Further studies are needed with a larger sample size comparing different implants and both techniques in terms of results and complications. It is not clear whether hyphema may be more frequent when the implant is placed in any of the two spaces but their appearance might be related to the long-term IOP results.

Conflict of Interest: None of the authors has conflict of interest

\section{References}

1- Muñoz G. Nonstitch suprachoroidal technique for T-flux implantation in deep sclerectomy.J Glaucoma. 2009; 18:262-264.

2- Bonilla R, Loscos J, Valldeperas X, Parera M A, Sabala A. Supraciliary hema implant in combined deep sclerectomy and phacoemulsification: one year results. Open Ophthalmol J. 2012; 6: 59-62.

3- Mermoud A, Shaarawy T. Non penetrating glaucoma surgery. London: Martin Dunitz; 2001; 97.

4- Development Core Team (2011): A language and environment for statistical computing. R Foundation for Statistical Computing, Vienna, Austria. Available on http://www.R-project.org/

5- Cheng J W, Ma XY, Wei RL. Efficacy of non-penetrating trabecular surgery for open angle glaucoma: a meta-analysis. Chin Med J. (Engl) 2004; 117:10061010. 
6- Lachkar Y, Neverauskiene J, Jeanteur-Lunel MN, et al. Nonpenetrating deep sclerectomy: a 6-year retrospective study. Eur J Ophthalmol. 2004; 14:26-36.

7- Ravinet E, Bovey E, Mermoud A. T-Flux implant versus Healon GV in deep sclerectomy. J Glaucoma. 2004; 13: 46-50.

8- Leszczyński R, Formińska-Kapuścik M, Bubała-Stachowicz B, MrukwaKominek E, Filipek E, Pawlicki K. Nonpenetrating very deep sclerectomy with hyaluronic acid implant vs trabeculectomy - a 2-year follow-up. Graefes Arch Clin Exp Ophthalmol. 2012; 250:1835-1841.

9- Grieshaber MC, Schoetzau A, Flammer J, Orgül S. Postoperative microhyphema as a positive prognostic indicator in canaloplasty. Acta Ophthalmol. 2013; 91(2):151-6.

10- Koch JM, Heiligenhaus A, Heinz C. Canaloplasty and transient anterior chamber haemorrhage. A prognostic factor?. Klin Monbl Augenheilkd. 2011;228: 465-467.

11- Hamel M, Shaarawy T, Mermoud A. Deep sclerectomy with collagen implant in patients with glaucoma and high myopia. J Cataract Refract Surg. $2001 ; 27: 1410-1417$.

12- Konstas AG, Jay JL. Modification of trabeculectomy to avoid postoperative hyphaema. The 'guarded anteriorfistula' operation. Br J Ophthalmol 1992; 76 : 353-357.

13- Coob CJ, Chakrabarti S, Chadha V, Sanders R. The effect of aspirin and warfarin therapy in trabeculectomy. Eye 2007; 21: 598-603.

14- Figus M, Bartolomei MP, Lazzeri S, Nardi M. Very deep sclerectomy. J Glaucoma. 2011; 20:67. 


\section{Tables}

\begin{tabular}{|c|c|}
\hline Age & $69 \pm 10$ \\
\hline Male & $28(68.3 \%)$ \\
\hline Female & $13(31.7 \%)$ \\
\hline Eye & \\
\hline - Right & $25(52.1 \%)$ \\
\hline - Left & $23(49.7 \%)$ \\
\hline Phakic & $34(70.8 \%)$ \\
\hline Pseudophakic & $14(29.2 \%)$ \\
\hline Glaucoma & \\
\hline - NTG & $2(4.2 \%)$ \\
\hline - POAG & $38(79.2 \%)$ \\
\hline - $P G$ & $5(10.4 \%)$ \\
\hline - PSXG & $3(6.2 \%)$ \\
\hline Preoperative BCVA $(n=48)$ & $0.6 \pm 0.3$ \\
\hline Postperative BCVA & \\
\hline - 12 months ( $\mathrm{n}=48)$ & $0.6 \pm 0.2$ \\
\hline - 24 months $(\mathrm{n}=33)$ & $0.7 \pm 0.2$ \\
\hline Preoperative IOP $(\mathrm{n}=48)$ & $24.6 \pm 0.6$ \\
\hline Postoperative IOP & \\
\hline - 12 months ( $n=48)$ & $16.5 \pm 4.4$ \\
\hline - 24 months $(\mathrm{n}=33)$ & $16.1 \pm 3.4$ \\
\hline Preoperative medications $(n=48)$ & $2.71 \pm 0.7$ \\
\hline Postoperative medications & \\
\hline - 12 months $(\mathrm{n}=48)$ & $0.2 \pm 0.1$ \\
\hline - 24 months $(n=33)$ & $0.4 \pm 0.1$ \\
\hline
\end{tabular}

Table 1: Clinical and demographic characteristics of patients included in this study (NTG: Normal Tension Glaucoma, POAG: Primary Open Angle Glaucoma, PG: Pigmentary Glaucoma. PSXG: Pseudoexfoliative Glaucoma, BCVA: Best corrected visual Acuity in Snellen decimal scale) 


\begin{tabular}{|c|c|c|c|c|}
\hline Intraoperatives & Early Postoper & 1 month) & Late Postoperatives (>1 & onth) \\
\hline Microperforation & $\begin{array}{l}\text { Seidel } 24 \text { hours } \\
\text { Seidel } 1 \text { week } \\
\text { Hyphema } \\
\text { Iris synechia } \\
\text { IOP } \geq 21 \mathrm{mmHg} \\
\text { CD } \\
\text { Bleb failure }\end{array}$ & $\begin{array}{l}11(22.91 \%) \\
2(4.16 \%) \\
7(14.58 \%) \\
1(2.08 \%) \\
4(8.32 \%) \\
3(6.25 \%) \\
2(4.16 \%)\end{array}$ & $\begin{array}{l}\text { Cataracts } \\
\text { Uveal prolapse } \\
\text { Goniopuncture } \\
\text { - } \quad \text { Iris Incarceration } \\
\text { - } \quad \text { Hypotony } \\
\text { - } \quad \text { Bleeding }\end{array}$ & $\begin{array}{l}1(6.25 \%) \\
2(4.16 \%) \\
30(62.5 \%) \\
1(2.08 \%) \\
1(2.08 \%) \\
7(14.8 \%)\end{array}$ \\
\hline
\end{tabular}

Table 2: Intra and postoperatives complications incluiding Goniopuncture (GP) and bleb related. (IOP:Intraocular pressure. CD: Choroidal detachment. )

\begin{tabular}{|c|c|c|c|c|c|c|c|c|}
\hline IOP & Preop & $\begin{array}{l}24 \text { hours } \\
(\mathrm{N}=48)\end{array}$ & $\begin{array}{c}1 \\
\text { month } \\
(\mathrm{N}=48)\end{array}$ & $\begin{array}{c}3 \\
\text { months } \\
(\mathrm{N}=48)\end{array}$ & $\begin{array}{c}6 \\
\text { months } \\
(\mathrm{N}=48)\end{array}$ & $\begin{array}{c}12 \\
\text { months } \\
(\mathrm{N}=48)\end{array}$ & $\begin{array}{c}18 \\
\text { months } \\
(\mathrm{N}=33)\end{array}$ & $\begin{array}{c}24 \\
\text { months } \\
(\mathrm{N}=33)\end{array}$ \\
\hline $\begin{array}{l}\text { Mean } \\
\text { SD }\end{array}$ & $\begin{array}{l}24.6 \\
6.33\end{array}$ & $\begin{array}{l}7.94 \\
6.55\end{array}$ & $\begin{array}{l}17.2 \\
5.73\end{array}$ & $\begin{array}{l}15.5 \\
4.28\end{array}$ & $\begin{array}{l}16.4 \\
4.11\end{array}$ & $\begin{array}{l}16.5 \\
4.47\end{array}$ & $\begin{array}{l}16.8 \\
4.36\end{array}$ & $\begin{array}{l}16.1 \\
3.43\end{array}$ \\
\hline $\begin{array}{l}\mathrm{N}^{\circ} \\
\text { Drugs }\end{array}$ & Preop & $\begin{array}{l}24 \text { hours } \\
(\mathrm{N}=48)\end{array}$ & $\begin{array}{c}1 \\
\text { month } \\
(\mathrm{N}=48)\end{array}$ & $\begin{array}{c}3 \\
\text { months } \\
(\mathrm{N}=48)\end{array}$ & $\begin{array}{c}6 \\
\text { months } \\
(\mathrm{N}=48)\end{array}$ & $\begin{array}{c}12 \\
\text { months } \\
(\mathrm{N}=48)\end{array}$ & $\begin{array}{c}18 \\
\text { months } \\
(\mathrm{N}=33)\end{array}$ & $\begin{array}{c}24 \\
\text { months } \\
(\mathrm{N}=33)\end{array}$ \\
\hline & 2.71 & 0 & 0 & 0.04 & 0.06 & 0.22 & 0.27 & 0.4 \\
\hline
\end{tabular}

Table 3: Intraocular pressure (IOP) evolution and numbers of medications. (SD: Standard desviation)

\begin{tabular}{|l|c|c|c|c|c|c|}
\hline Hyphema 12 m & N & Mean & SD & Median & Minimum & Maximum \\
\hline No & 41 & 16.0 & 4.4 & 16 & 6 & 25 \\
\hline Yes & 7 & 19.3 & 4.3 & 19 & 12 & 26 \\
\hline Hyphema 24 m & $\mathbf{N}$ & Mean & SD & Median & Minimum & Maximum \\
\hline No & 27 & 15.6 & 3.5 & 16.0 & 5 & 21 \\
\hline Yes & 6 & 18 & 2.8 & 16.5 & 16 & 22 \\
\hline
\end{tabular}

Table 4: Intraocular pressure in eyes with / without Hyphema at 12 and 24 months. (SD: Standard desviation). 


\section{Figures legend}

Figure1: Box Plot Eyes with/without hyphema at 12 months.

Figure 2: Box Plot Eyes with/without hyphema at 24 months.

Figure 3: Ultrasound biomicroscopy: Uveal prolapse (Blue arrow). Absense of hyporeflective suprachoroidal space and conjuntival bleb.

Figure 4 Ultrasound biomicroscopy : Uveal prolapse (Black arrow) with good location of the implant, presence of hyporeflective suprachoroidal space (Red arrow) and conjunctival bleb (Blue arrow).

Figure 1

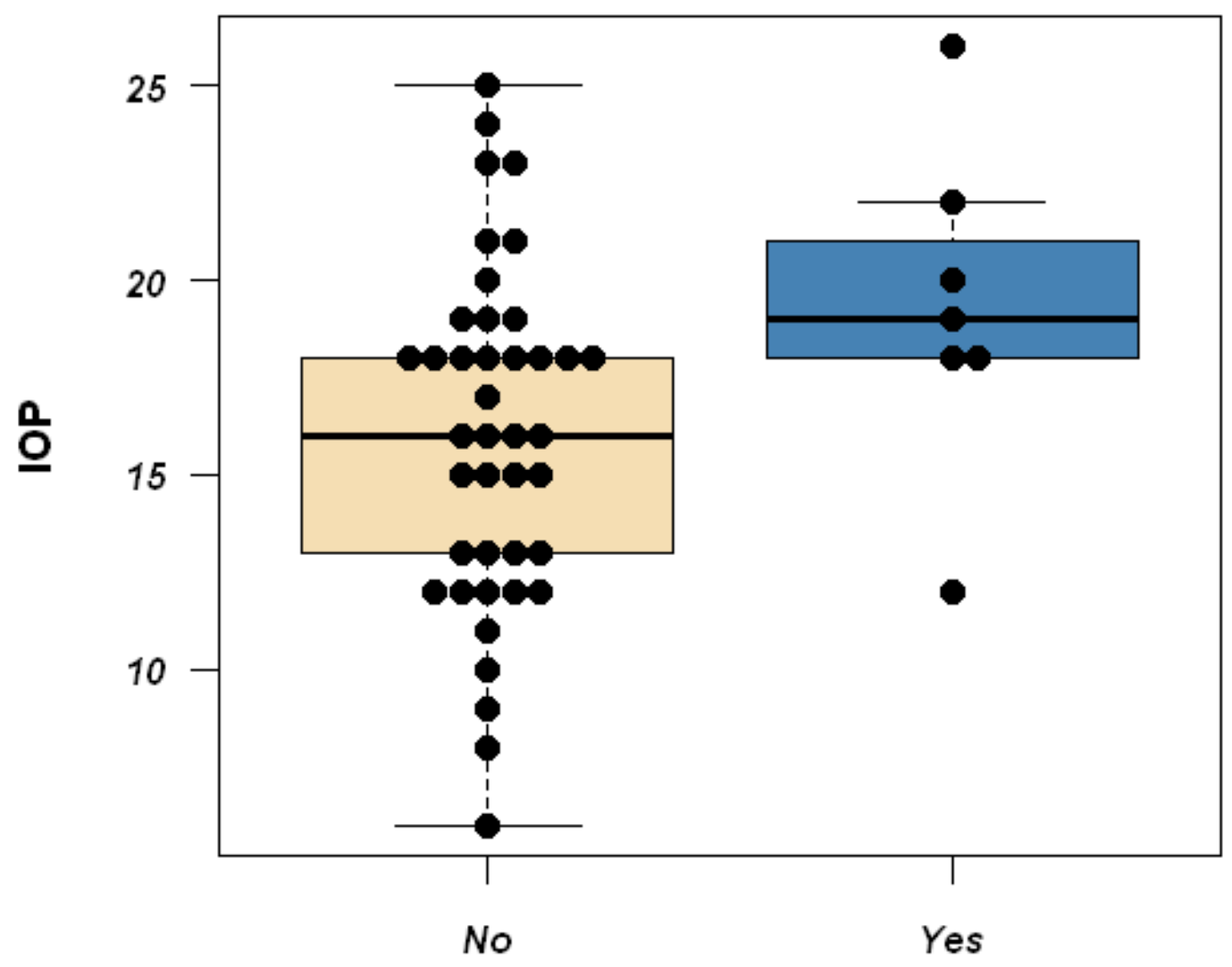

Hyphema 
Figure 2

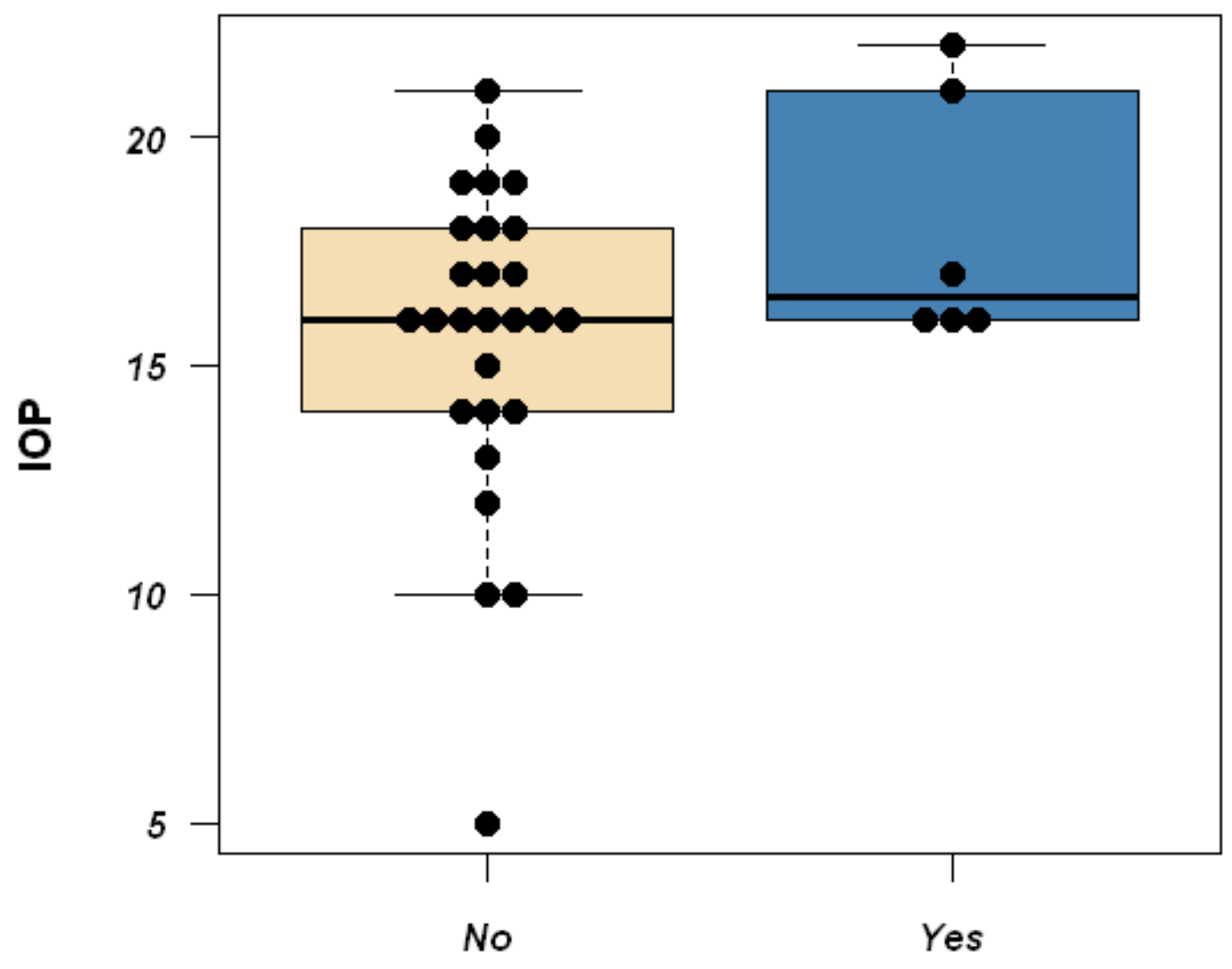

Hyphema 
Figure 3

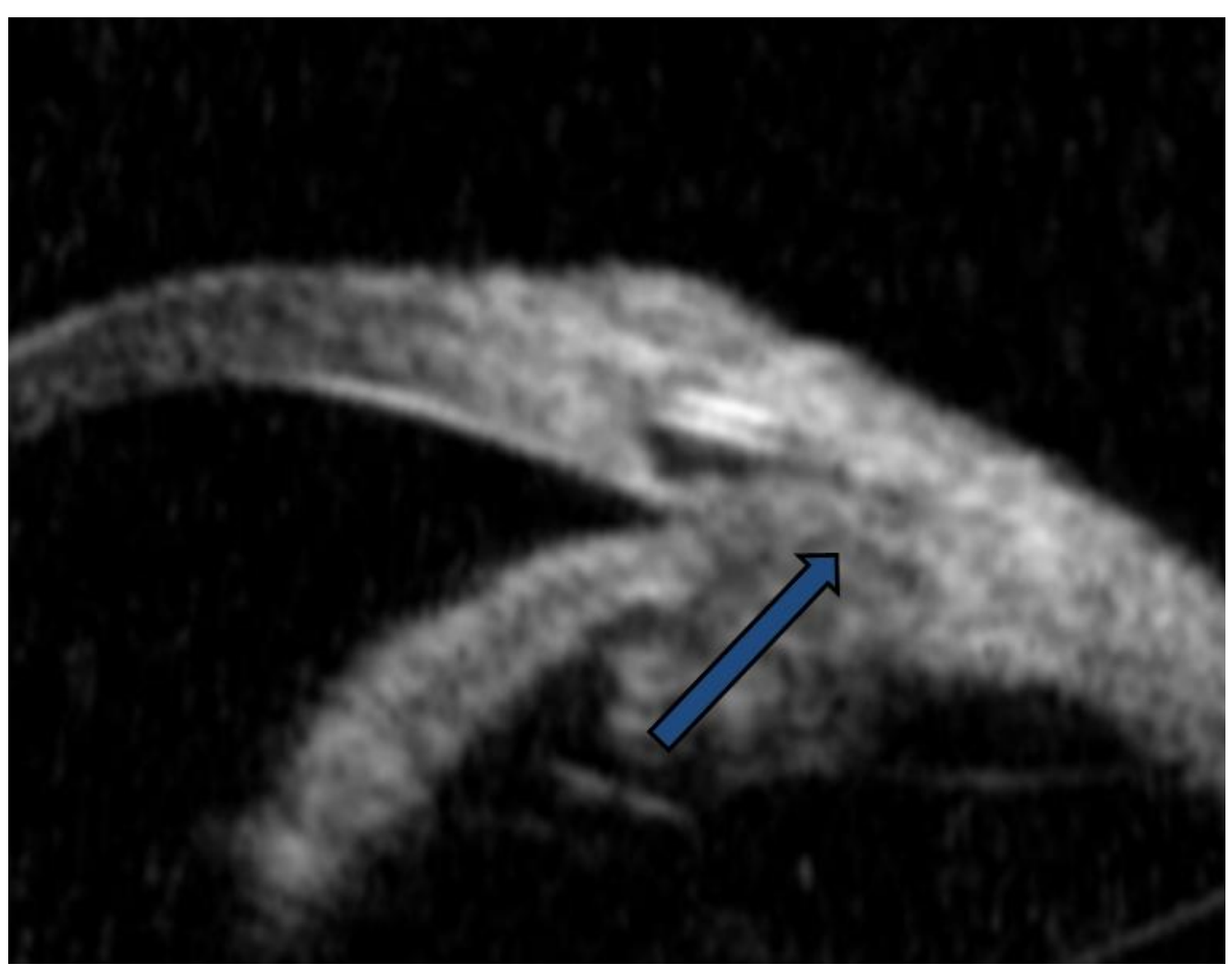


Figure 4

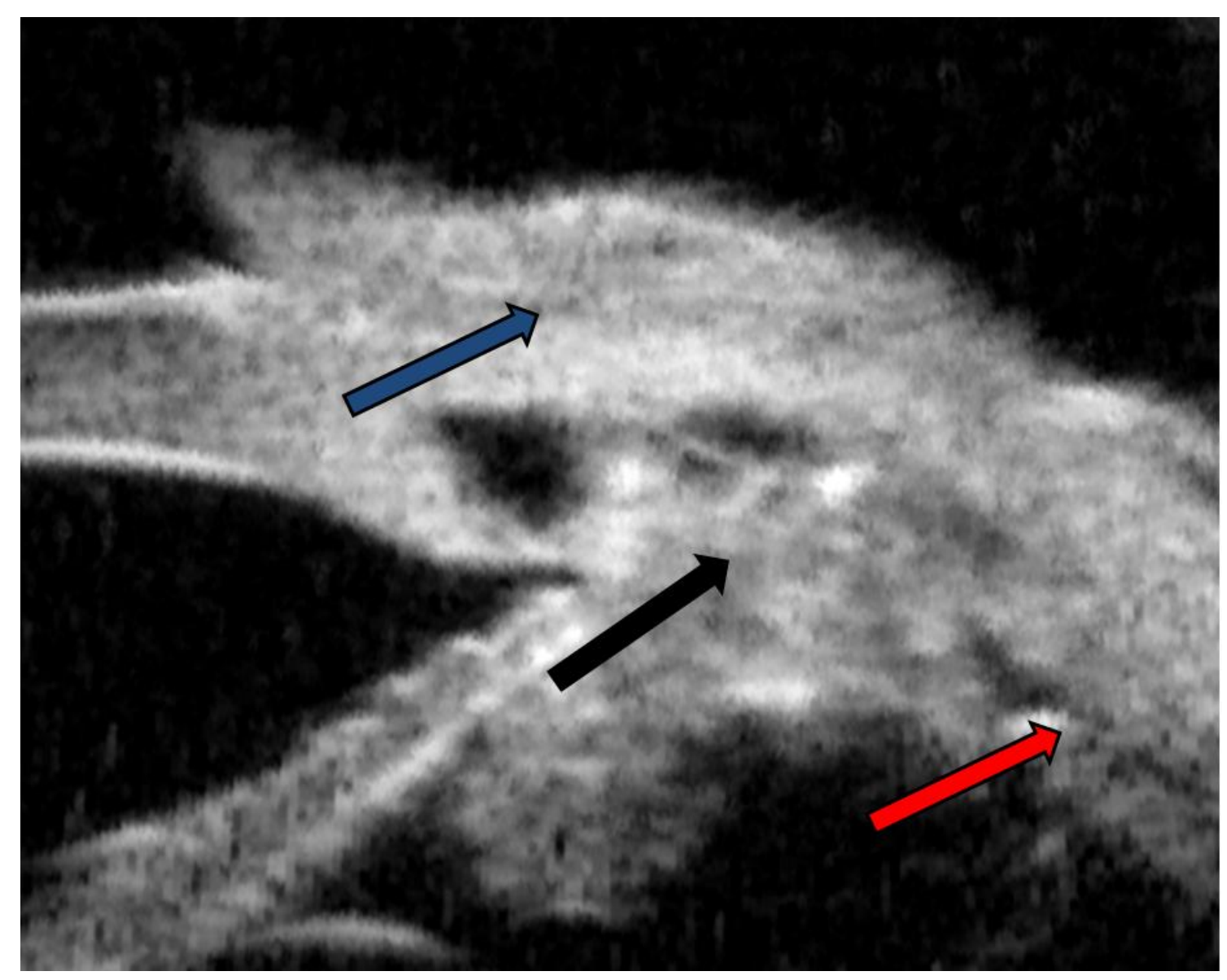

